\title{
Densidades de Plantas Daninhas e Épocas de Controle sobre os Componentes de Produção da Soja ${ }^{1}$
}

\author{
Effect of Weed Densities and Control Periods on Soybean Yield Components
}

\author{
SILVA, A.F. ${ }^{2}$, FERREIRA, E.A. ${ }^{3}$, CONCENÇO, G. ${ }^{3}$, FERREIRA, F.A. ${ }^{4}$, ASPIAZU, ${ }^{3}{ }^{3}$, GALON, L. ${ }^{3}$, \\ SEDIYAMA, T. ${ }^{4}$ e SILVA, A.A. ${ }^{4}$
}

\begin{abstract}
RESUMO - Este trabalho foi conduzido com o objetivo de determinar os efeitos de diferentes densidades de plantas daninhas sobre os componentes de rendimento da soja, cv. BRS 243RR. O delineamento experimental foi em blocos ao acaso, sendo os tratamentos constituidos pela combinação entre dez períodos crescentes de convivência das plantas daninhas com a cultura (0, 0-5, 0-10, 0-15, 0-21, 0-28, 0-35, 0-42, 0-49 e 0-125 dias) e três niveis de infestação (baixa, média e alta). Na área de baixa infestação, a comunidade infestante foi composta principalmente por Brachiaria plantaginea, Ipomoea nil, Euphorbia heterophylla e outras. Nas áreas de média e alta infestação destacaram-se Brachiaria plantaginea, Ipomoea nil, Digitaria horizontalis, Cyperus rotundus e outras. B. plantaginea foi responsável pelo maior acúmulo de fitomassa seca em todos os niveis de infestação. Com relação aos componentes de produção, o número de vagens por planta foi o mais afetado pela competição, com reduções de até $58 \%$ na área de baixa infestação, $71 \%$ na de média infestação e $78 \%$ na de alta infestação. O número de sementes por vagens e peso de mil grãos se mostraram menos responsivos aos efeitos de competição; contudo, houve redução desses parâmetros, indicando relação entre o período de convivência e nivel de infestação e os componentes de produção da soja.
\end{abstract}

Palavras-chave: competição, Glycine max, produtividade.

\begin{abstract}
This work aimed to evaluate the effects of different weed densities on the yield components of soybean grain, $c v . B R S 243-R R$. The experimental design was arranged in completely randomized blocks, and the treatments consisted of increasing periods of control and three weed densities (low, medium and high). The initial periods of control were: $0,0-5,0-10,0-15,0-21,0-$ 28, 0-35, 0-42, 0-49 and 0-125 (harvesting). In low infestation areas, the weed community was composed mainly of Brachiaria plantaginea, Ipomoea nil, Euphorbia heterophylla and others. In medium and high infestation areas, the outstanding weeds were Brachiaria plantaginea, Ipomoea nil, Digitaria horizontalis, Cyperus rotundus and others. B. plantaginea was responsible for the highest dry matter accumulation in all levels of infestation. Regarding the crop yield components, number of pods per plant was the most severely affected by competition, reduced at about $58 \%$ in the low infestation area, $71 \%$ in the medium infestation area and $78 \%$ in the high infestation area. Number of seeds per pod and weight of 1000 grains were less influenced by competition; however, these parameters were reduced, indicating a relation between weed control periods and infestation level with soybean yield component.
\end{abstract}

Keywords: competition, Glycine max, yield

1 Recebido para publicação em 3.9.2007 e na forma revisada em 27.2.2008.

2 Mestrando do Programa de Pós-Graduação em Fitotecnia da Universidade Federal de Viçosa- UFV, <afsagro@yahoo.com.br> (autor para correspondência); ${ }^{3}$ Doutorando do Programa de Pós-Graduação em Fitotecnia da Universidade Federal de ViçosaUFV; ${ }^{4}$ Prof. do Dep. de Fitotecnia UFV. 


\section{INTRODUÇÃO}

A presença de plantas daninhas em lavouras de soja pode afetar o desenvolvimento da cultura, por promover competição pelos recursos do meio, como água, luz e nutrientes, reduzindo a disponibilidade desses recursos para a cultura e causando redução na produtividade de grãos, devido aos efeitos da interferência sobre as variáveis que definem a produtividade da cultura.

A época de início do controle de plantas daninhas tem grande influência no crescimento das plantas e na produtividade de grãos da soja (Rizzardi et al., 2004). Os efeitos negativos da comunidade infestante em culturas decorrem tanto do aumento na densidade de plantas daninhas quanto da duração do período de interferência (Ghersa \& Holt, 1995). Em relação à densidade, Vandevender et al. (1997) observaram que, com o incremento na densidade de plantas daninhas, diminuía-se o rendimento em arroz irrigado. Rizzardi et al. (2003) verificaram que o grau de interferência exercido por plantas daninhas dicotiledôneas na cultura da soja depende da espécie daninha presente e de sua densidade.

Na prática, os efeitos da interferência são irreversiveis, não havendo recuperação do desenvolvimento ou da produtividade após retirada do estresse causado pela presença das plantas daninhas (Koslowski et al., 2002). Os efeitos decorrentes da interferência de plantas daninhas sobre características de plantas cultivadas podem comprometer o desenvolvimento de estruturas reprodutivas e afetar os componentes da produtividade de grãos (Lamego et al., 2004). Segundo Board et al. (1995), em soja, o número de vagens é a característica mais responsiva às alterações causadas pelo estresse da competição de espécies concorrentes, enquanto o número de grãos por vagem e o peso médio de grãos possuem maior controle individual, mostrando pequena amplitude de variação devido ao ambiente.

Diversos trabalhos relatam o efeito negativo da competição de plantas daninhas sobre os componentes de produção da soja. Juan et al. (2003) relataram a redução de $40 \%$ no número de vagens por planta, de $6,5 \%$ no número grãos por vagens e de $10 \%$ no peso de mil grãos quando a cultura teve interferência de Euphorbia dentata na densidade de 55 plantas $\mathrm{m}^{-2}$. Lamego et al. (2004) observaram redução do número de vagens por área quando os cultivares foram submetidos à interferência e Meschede et al. (2004) demonstraram que a matéria seca da comunidade infestante possui correlação significativa e inversamente proporcional a altura, número de hastes por planta, estande final e produtividade.

Este trabalho teve por objetivo avaliar os efeitos da interferência das plantas daninhas sobre os componentes de produção da cultura da soja (cv. BRS 243-RR): altura, número de vagens/planta, número de sementes/planta e peso de mil grãos, quando cultivada em áreas com três niveis de infestação.

\section{MATERIAL E MÉTODOS}

O experimento foi conduzido nos sistemas de plantios convencional e direto em um Argissolo Vermelho-Amarelo câmbico, no período de novembro de 2006 a março de 2007, na Estação Experimental da Universidade Federal de Viçosa, localizada no municipio de CoimbraMG (2051' de latitude sul, 42 ${ }^{\circ} 46^{\prime}$ de longitude oeste e $651 \mathrm{~m}$ de altitude). A área de baixa infestação correspondeu ao sistema de plantio direto, e as áreas de média e alta infestação foram conduzidas em sistema convencional de semeadura. A análise das amostras de solo, coletadas antes da instalação do experimento na área destinada ao plantio convencional, apresentou as seguintes características químicas (Tabela 1).

Antecedendo a instalação dos ensaios, foi realizada a dessecação química com os herbicidas glyphosate $+2,4-\mathrm{D}\left(1.440+470 \mathrm{~g} \mathrm{ha}^{-1}\right.$, respectivamente) em mistura no tanque, dez dias antes da semeadura. No ensaio referente ao plantio convencional, essa vegetação foi incorporada pelo preparo mecânico do solo com uma aração e duas gradagens, sete dias antes da semeadura, enquanto no plantio direto ela permaneceu na superficie do solo.

O cultivar de soja utilizado foi o BRS 243$\mathrm{RR}$, semeado no espaçamento de $0,50 \mathrm{~m}$ entre linhas, depositando-se 13,5 sementes por metro linear, sendo utilizados $40 \mathrm{~kg} \mathrm{ha}^{-1}$ da formulação 8-28-16 (N-P-K) na linha de plantio. Os dados climatológicos do período de condução do ensaio estão apresentados na Figura 1. 
Densidades de plantas daninhas e épocas de controle sobre...

Tabela 1 - Composição química da camada de 0-10 cm de profundidade do solo argiloso proveniente dos sistemas de plantio direto e convencional utilizados no experimento. Coimbra-MG, 2006

\begin{tabular}{|c|c|c|c|c|c|c|c|}
\hline \multicolumn{8}{|c|}{ Sistema de plantio direto } \\
\hline \multicolumn{8}{|c|}{ Análise química } \\
\hline $\mathrm{pH}$ & $\mathrm{P}$ & $\mathrm{K}^{+}$ & $\mathrm{H}+\mathrm{Al}$ & $\mathrm{Ca}^{2+}$ & $\mathrm{Mg}^{2+}$ & $\mathrm{CTC} \mathrm{Tt}$ & $\mathrm{MO}$ \\
\hline$--\mathrm{H}_{2} \mathrm{O}--$ & \multicolumn{2}{|c|}{------ $\mathrm{mg} \mathrm{dm}^{-3}$------ } & \multicolumn{4}{|c|}{ - } & ----- dag $\mathrm{kg}^{-1}$----- \\
\hline 5,0 & 7,1 & 59 & 2,6 & 2,3 & 0,6 & 5,65 & 1,07 \\
\hline \multicolumn{8}{|c|}{ Sistema de plantio convencional } \\
\hline \multicolumn{8}{|c|}{ Análise química } \\
\hline $\mathrm{pH}$ & $\mathrm{P}$ & $\mathrm{K}^{+}$ & $\mathrm{H}+\mathrm{Al}$ & $\mathrm{Ca}^{2+}$ & $\mathrm{Mg}^{2+}$ & CTC Tt & MO \\
\hline$--\mathrm{H}_{2} \mathrm{O}--$ & \multicolumn{2}{|c|}{----- $\mathrm{mg} \mathrm{dm}{ }^{3}$----- } & \multicolumn{4}{|c|}{ 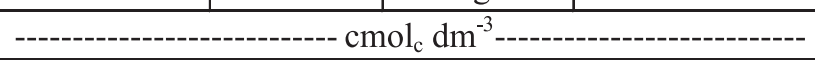 } & ----- dag kg-1 ----- \\
\hline 5,0 & 9,6 & 50 & 2,5 & 2,0 & 0,5 & 5,12 & 1,01 \\
\hline
\end{tabular}

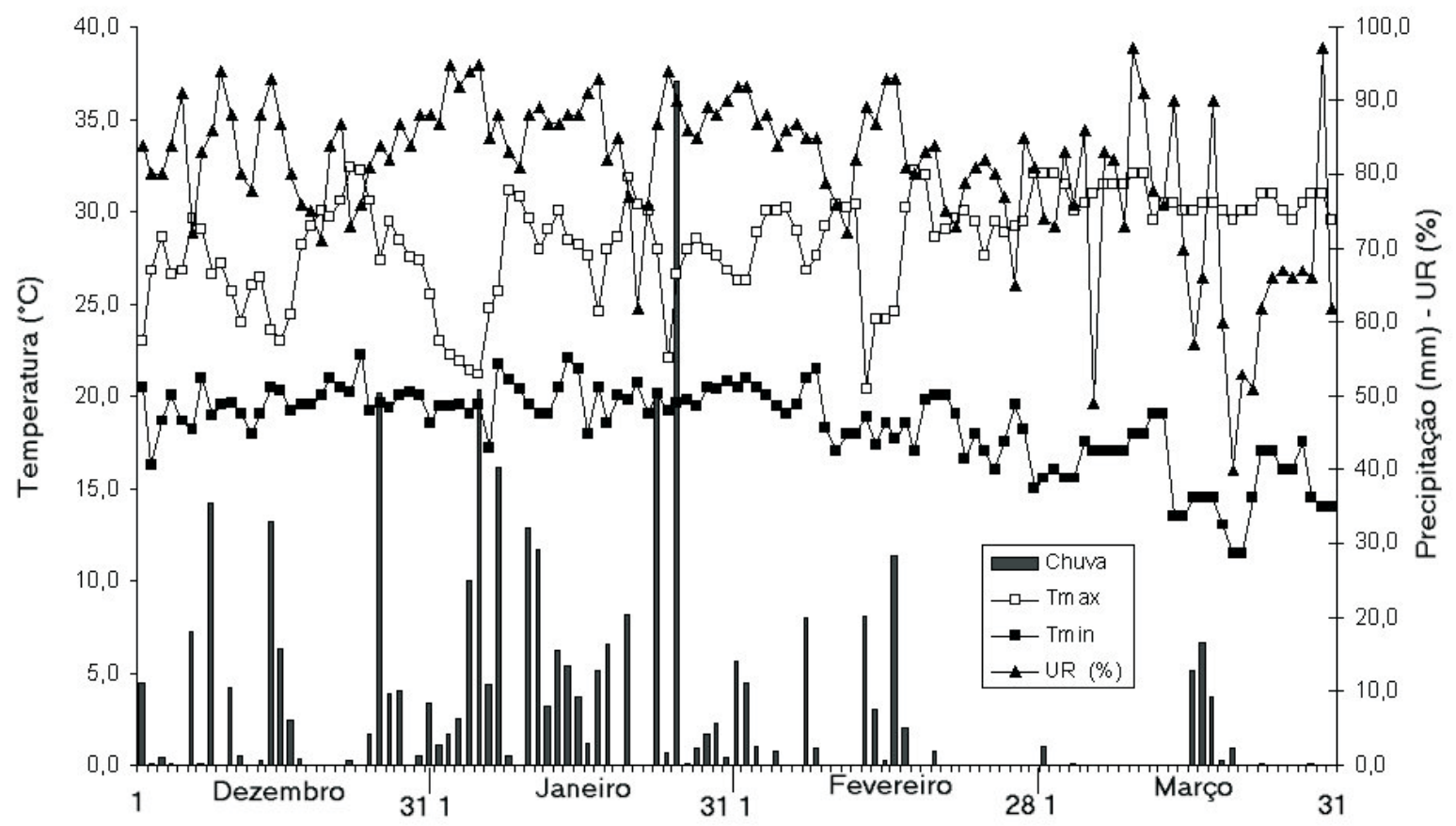

Figura 1 - Dados climáticos observados na área experimental durante a realização do experimento: precipitação pluvial, temperaturas máxima e mínima e umidade relativa do ar.

Em ambos os sistemas de cultivo a cultura da soja ficou em convivência com as plantas daninhas por diferentes períodos do seu ciclo de desenvolvimento: $0,5,10,14,21,28,35$, 42,49 e 125 dias (todo o ciclo da cultura), totalizando assim dez tratamentos em cada nivel de infestação. Após o término de cada período inicial de convivência, foi realizado o controle das plantas daninhas até a colheita, com aplicações de glyphosate sempre que necessário para manter as parcelas no limpo. O delineamento experimental adotado foi em blocos casualizados, com dez tratamentos e quatro repetições. As parcelas foram constituídas por seis linhas de três metros de comprimento, com espaçamento de $0,5 \mathrm{~m}$. A área útil para avaliação foi constituída das quatro linhas centrais e teve como bordadura uma linha de 
plantio de cada lado e meio metro de cada uma das extremidades, perfazendo $4,0 \mathrm{~m}^{2}$.

As avaliações da densidade e da matéria seca das plantas daninhas foram realizadas no final de cada período de convivência. Essas avaliações foram feitas com o lançamento aleatório de quadrado metálico de 0,25 m de lado, por quatro vezes, na área útil de cada parcela. As partes aéreas das plantas daninhas foram coletadas e separadas por espécie, determinando-se os valores de densidade e massa seca. A massa seca foi obtida pela secagem em estufa com ventilação forçada de ar a $70{ }^{\circ} \mathrm{C}$, até atingir massa constante.

Para verificar a interferência de plantas daninhas nas variáveis que definem os componentes de produção, foram coletadas dez plantas de soja por parcela e, nestas, avaliados: número de vagens por planta, número de sementes por vagem e peso de mil sementes com o teor de umidade padronizado em 13\%.

Os resultados de densidade e acúmulo de fitomassa seca da comunidade da infestante foram analisados através do desvio-padrão de suas médias. Os componentes de produção foram submetidos à análise de regressão.

\section{RESULTADOS E DISCUSSÃO}

A utilização do sistema de plantio direto reduz drasticamente o revolvimento mecânico do solo e mantém os resíduos culturais na sua superfície. A não-incorporação dos materiais vegetais presentes na superficie do solo provoca alterações na dinâmica do banco de sementes das plantas daninhas, influenciando a quebra da dormência, a germinação e a ação dos microrganismos (Silva et al., 2005). Os efeitos diferenciados dos sistemas de preparo do solo sobre as plantas daninhas podem modificar a composição botânica da comunidade (Jakelaitis et al., 2003). Essas modificações podem ser simples flutuações populacionais associadas a alterações temporárias ou podem ser definitivas, apresentando comportamento semelhante ao fenômeno da sucessão ecológica. Dependendo da intensidade, essas alterações podem afetar o manejo, o controle e a competição exercida por essa comunidade com a cultura (Ghersa et al., 2000).
A comunidade infestante se mostrou diferente de acordo com o sistema de cultivo adotado. A área de baixa infestação foi composta basicamente por quatro espécies: leiteiro (Euphorbia heterophylla), corda-de-viola (Ipomoea sp.), capim-marmelada (Brachiaria plantaginea) e outras. Dentre estas espécies, $B$. plantaginea se destacou, sendo responsável por $80 \%$ da fitomassa seca total produzida pelas plantas na área de baixa infestação. Trata-se de uma das mais agressivas gramineas infestantes, ocorrendo em inúmeras culturas, sendo particularmente importante na cultura da soja. A presença dessa graminea afeta diretamente o rendimento das culturas. Em condições de solo fértil, o desenvolvimento pode ser tão vigoroso que uma planta por $\mathrm{m}^{2}$ chega a reduzir em $50 \%$ o rendimento da soja. O prejuízo varia conforme o porte da cultura, a duração do período de competição e as condições edafoclimáticas. Na colheita têm-se novos prejuizos, pois a invasora apresenta ciclo mais longo que o das culturas anuais e a presença de grande massa foliar dificulta ou impede o funcionamento das colheitadeiras, além de aumentar o teor de umidade dos grãos (Kissmann, 1997).

Nas áreas de média e alta infestação a comunidade infestante foi composta basicamente por cinco espécies: corda-de-viola (Ipomoea sp.), capim-colchão (Digitaria horizontalis), capim-marmelada (Brachiaria plantaginea), tiririca (Cyperus rotundus) e outras. Dentre as espécies que compuseram a comunidade infestante, duas se destacaram: $B$. plantaginea e $C$. rotundus, sendo responsáveis por 60,23 e $31,38 \%$, respectivamente, da fitomassa seca total produzida na área de média infestação e por 53,22 e 37,60\%, respectivamente, da fitomassa seca total produzida na área de alta infestação. C. rotundus se caracteriza por possuir alta capacidade de infestação e de liberação de aleloquímicos no solo (Quayyum et al., 2000), podendo causar interferência negativa no crescimento e desenvolvimento da cultura; a sua importância fica ainda mais evidente por ser uma espécie de dificil controle químico e/ou mecânico.

Analisando a densidade (Figura 2) e o acúmulo de fitomassa seca da comunidade infestante (Figura 3) nos três niveis de infestação, em resposta aos períodos de convivência, 
verificou-se que na área de baixa infestação a densidade máxima foi alcançada aos 49 dias após a emergência (DAE) da cultura da soja, com as plantas daninhas atingindo densidade de 238 plantas $\mathrm{m}^{-2}$. Nas áreas de média e alta infestação a densidade máxima foi alcançada aos 28 DAE: 307 e 656 plantas $\mathrm{m}^{-2}$, respectivamente; a partir de então, houve diminuição da densidade total até o último dia da avaliação (254 e 412 plantas $\mathrm{m}^{-2}$ nas áreas de média e alta infestação, respectivamente). Observouse redução mais acentuada da comunidade infestante nas áreas de alta infestação, o que pode ser explicado pela competição mais acirrada pelos recursos, especialmente luz. A fitomassa seca total dos três niveis de infestação apresentou crescimento ao longo de todo o período da avaliação, havendo maior acúmulo na área de alta $\left(437,05 \mathrm{~g} \mathrm{~m}^{-2}\right)$, média $\left(356,11 \mathrm{~g} \mathrm{~m}^{-2}\right)$ e baixa infestação $\left(187,49 \mathrm{~g} \mathrm{~m}^{-2}\right)$, no final do período avaliado. Esse comportamento é explicado por Radosevich et al. (1997), para os quais, à medida que aumenta a densidade e ocorre o desenvolvimento das plantas daninhas, sobretudo daquelas que germinaram e emergiram no início do ciclo da cultura, intensifica-se a competição inter e intra-específica, de modo que as plantas daninhas mais altas e desenvolvidas tornam-se dominantes, ao passo que as menores são suprimidas ou morrem. Esse comportamento de uma comunidade infestante explica a redução da densidade de plantas com o aumento da fitomassa seca durante o desenvolvimento da cultura.

Em ecossistemas agrícolas, a cultura e as plantas daninhas possuem suas demandas por

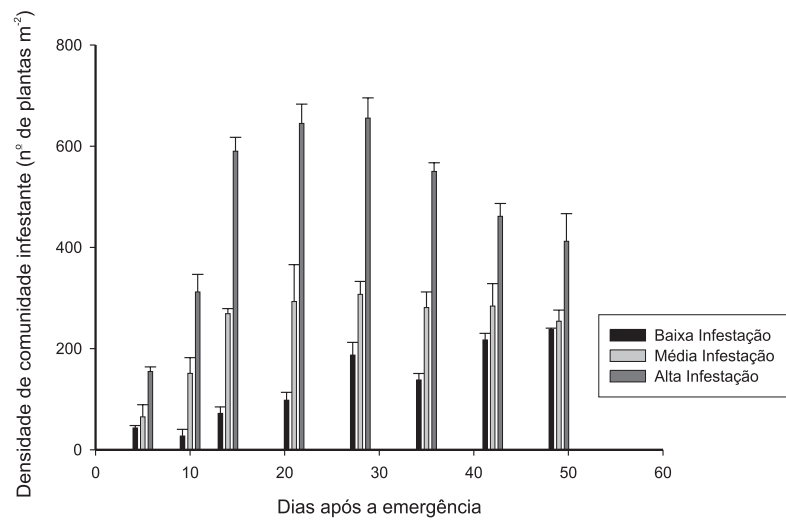

Figura 2 - Densidade de plantas daninhas nas áreas de baixa, média e alta infestação, em diferentes épocas após emergência da soja. água, luz, nutrientes e $\mathrm{CO}_{2}$. Pelo fato de na maioria das vezes esses fatores de crescimento (ou pelo menos um deles) estarem disponíveis em quantidade insuficiente até mesmo para o próprio desenvolvimento da cultura, estabelece-se a competição (Radosevich et al., 1997). Considerando que neste trabalho, como pode ser observado na Figura 1, durante o desenvolvimento da cultura da soja, ocorreu na área experimental elevada precipitação pluvial com boa distribuição, acredita-se que a competição tenha se estabelecido principalmente por luz, nutrientes e $\mathrm{CO}_{2}$. Nessa condição, segundo Radosevich et al. (1997), outros fatores, como a limitação de espaço, aéreo e subterrâneo, promovida pelas plantas daninhas, podem também afetar o crescimento e desenvolvimento das plantas cultivadas.

Com relação aos efeitos da competição nos componentes de rendimento, observou-se que o número de vagens por planta (Figura 4) foi o componente mais severamente afetado pela comunidade infestante; mesmo em condições de baixa infestação, já nos primeiros dias de convivência houve redução do número de vagens. Nas áreas de baixa, média e alta infestação, no final do ciclo da soja verificou-se redução de até 58,71 e $78 \%$, respectivamente, no número de vagens por planta. Esses resultados estão de acordo com os observados por Juan et al. (2003) e Lamego et al. (2004).

Quanto ao peso de mil grãos (Figura 5) para a soja cultivada em condição de baixa infestação com até 49 dias de convivência com a comunidade infestante, ele não foi afetado. Efeito

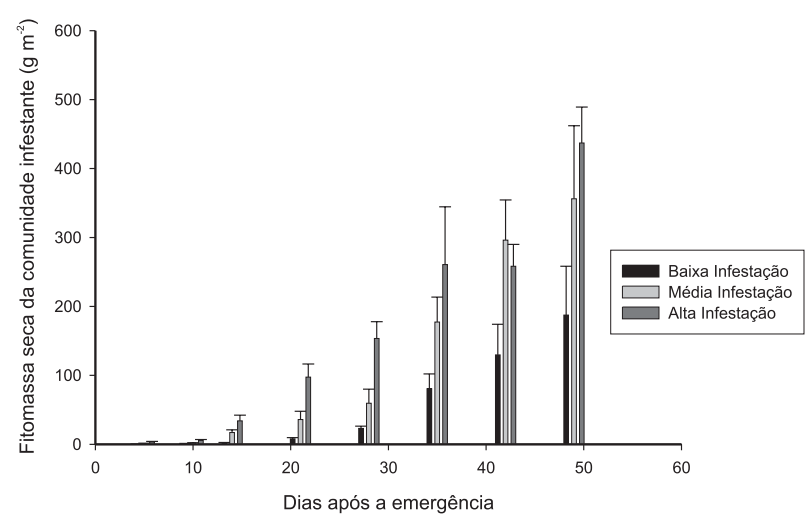

Figura 3 - Fitomassa seca de plantas daninhas nas áreas de baixa, média e alta infestação, em diferentes épocas após emergência da soja.

Planta Daninha, Viçosa-MG, v. 26, n. 1, p. 65-71, 2008 
significativo apenas foi observado quando a cultura conviveu durante todo o ciclo com a comunidade infestante. Neste caso, verificouse redução de $14 \%$ nessa variável. Nas áreas de média e alta infestação, observou-se redução do peso de mil grãos já nos primeiros dias de convivência da soja com a comunidade infestante, indicando que houve competição mais acirrada pelos recursos do meio. Neste caso, observou-se redução de até $21 \%$ na área de média e $24 \%$ nas áreas de média e alta infestação (Figura 6).

No que se refere aos efeitos de períodos de competição sobre o número de sementes por vagens na área de baixa infestação, até os 49 de convivência da cultura não se verificou efeito da competição. Todavia, esse efeito ocorreu quando a cultura conviveu durante todo o ciclo com a comunidade infestante. Na área de média infestação foi observada redução do número de sementes por vagens a partir dos 49 dias de interferência e, na de alta infestação, a partir dos $42 \mathrm{DAE}$, de acordo com o modelo de análise de regressão adotado.

Pode-se atribuir o melhor desempenho da soja na área de baixa infestação (plantio direto) não só à menor interferência imposta pela comunidade infestante, como também a uma série de outras características benéficas que este sistema de cultivo proporciona.

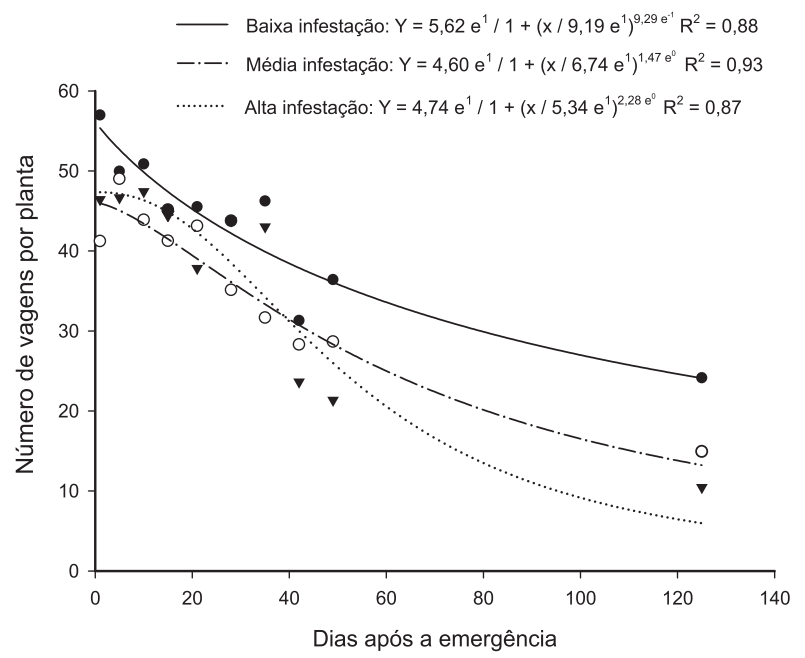

Figura 4 - Número de vagens/planta obtido em função de diferentes períodos de convivência com plantas daninhas nas áreas de baixa, média e alta infestação, após emergência da soja.
Diversos estudos têm demonstrado maior presença de inimigos naturais e maior atividade microbiana nas áreas de plantio direto (Cividanes, 2002; Balota, 2003; Santos et al., 2005; Pereira et al., 2007). Esse fato pode estar relacionado com os fatores abióticos do solo, como o aumento da umidade, o incremento dos teores de matéria orgânica e a diminuição das temperaturas máximas do solo, favorecendo o crescimento destes (Salton \& Mielniczuk, 1995).

A biomassa microbiana é responsável pelo controle de funções essenciais no solo, como decomposição e acúmulo de matéria orgânica, ou transformações envolvendo nutrientes minerais ou compostos no solo (Santos et al., 2005). O fato de o plantio direto normalmente apresentar maior biomassa microbiana pode proporcionar maior estocagem de nutrientes, possibilitando também melhor ciclagem destes ao longo do tempo, criando características mais favoráveis ao desenvolvimento das plantas (Stenberg, 1999).

Concluiu-se ser diferente o período anterior à interferência para diferentes niveis de infestação, existindo relação entre os sistemas de cultivo adotado, períodos de convivência da cultura da soja com as plantas daninhas e seus efeitos sobre os diferentes componentes de produção (número de vagens/planta,

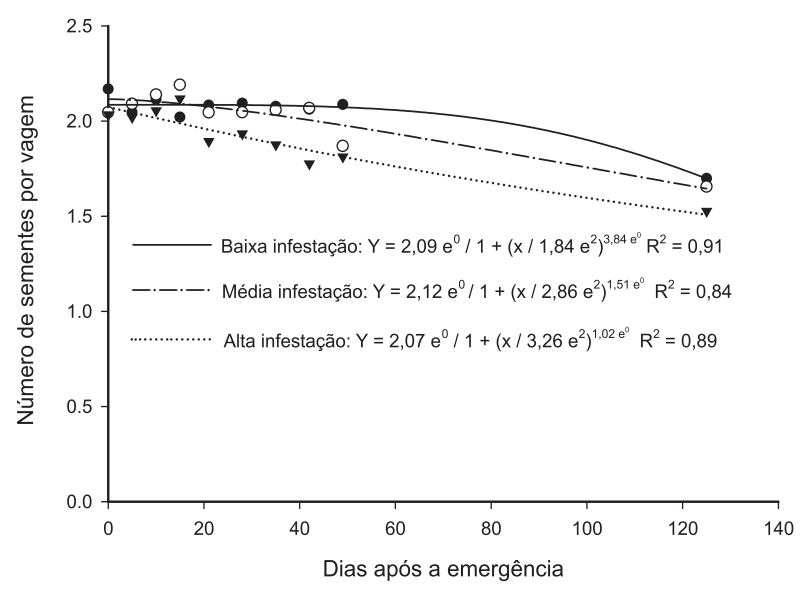

Figura 5 - Número de sementes/vagem obtido em função de diferentes períodos de convivência com plantas daninhas nas áreas de baixa, média e alta infestação, após emergência da soja. 


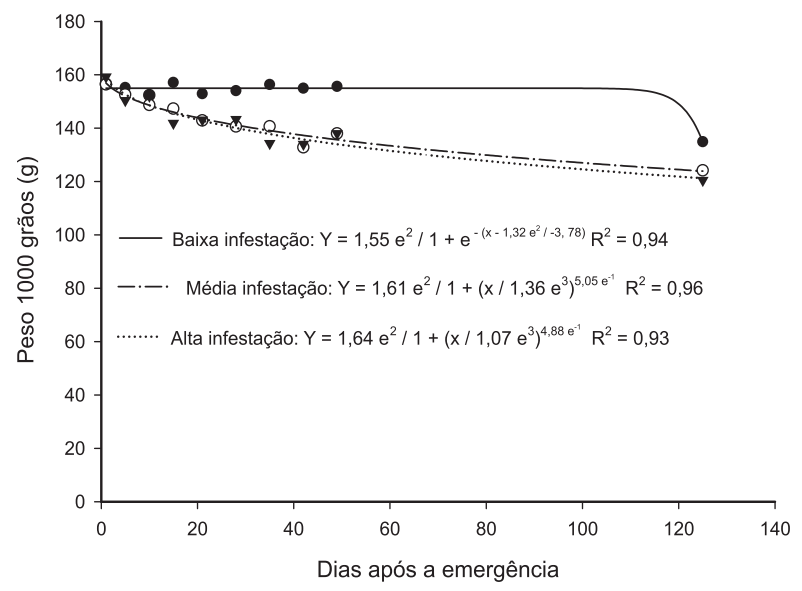

Figura 6 - Peso de 1.000 grãos obtido em função de diferentes períodos de convivência com plantas daninhas nas áreas de baixa, média e alta infestação, após emergência da soja.

número de sementes/vagem e peso de mil grãos). Entretanto, o componente de produção mais sensivel à interferência das plantas daninhas foi o número de vagem/planta.

\section{LITERATURA CITADA}

BALOTA, E. L. et al. Microbial biomass in soils under different tillage and crop rotation systems. Biol. Fert. Soil, v. 38, n. 1 , p. $15-20,2003$.

BOARD, J. E.; WIER, A. T.; BOETHEL, D. J. Source strength influence on soybean formation during early and late reproductive development. Crop. Sci., v. 35, n. 4, p. 1104-1110, 1995.

CIVIDANES, F. J. Efeitos do sistema de plantio e da consorciação soja-milho sobre artrópodes capturados no solo. Pesq. Agropec. Bras., v. 37, n. 1, p. 15-23, 2002.

GHERSA, C. M. et al. Advances in weed management strategies. Field Crops Res., v. 67, n. 2, p. 95-104, 2000.

GHERSA, C. M.; HOLT, J. S. Using phenology prediction in weed management: a review. Weed Res., v. 35, n. 6, p. $461-470,1995$

JAKELAITIS, A. et al. Dinâmica populacional de plantas daninhas sob diferentes sistemas de manejo nas culturas de milho e feijão. Planta Daninha, v. 21, n. 1, p. 71-79, 2003.

JUAN, V. F.; SAINT-ANDRE, H.; FERNANDEZ, R. R. Competencia de lecheron (Euphorbia dentata) en soja. Planta Daninha, v. 21, n. 2, p. 175-180, 2003

KISSMANN, K. G. Plantas infestantes e nocivas. 2.ed. São Paulo: Basf Brasileira, 1997. Tomo I. p. 415-420.
KOSLOWSKI, L. A. et al. Interferência das plantas daninhas na cultura do feijoeiro comum em sistema de semeadura direta. Planta Daninha, v. 20, n. 2, p. 213-220, 2002.

LAMEGO, F. P. et al. Tolerância a interferência de plantas competidoras e habilidade de supressão por genótipos de soja - II. Resposta de variáveis de produtividade. Planta Daninha, v. 22, n. 4, p. 491-498, 2004.

MESCHEDE, D. K. et al. Período anterior a interferência de plantas em soja: estudo de caso com baixo estande e testemunhas duplas. Planta Daninha, v. 22, n. 2, p. 239246, 2004.

PEREIRA, J. L. et al. Growth inhibitory effects of nutgrass (Cyperus rotundus) on rice (Oryza sativa) seedlings.

J. Chem. Ecol., v. 26, n. 9, p. 2221-2231, 2007.

QUAYYUN et al. Growth inhibitor effects of nutgrass (Cyperus rotundus) on rice (Oryza sativa) seedlings.

J. Chem. Ecol., v. 26, n. 9, p. 2221-2231, 2000.

RADOSEVICH, S. R..; HOLT, J.; GHERSA, C. Weed ecology: implications for management. 2.ed. New York: John Wiley \& Sons, 1997. 589 p.

RIZZARDI, M. A.; FLECK, N. G. Métodos de qualificação da cobertura foliar da infestação de plantas daninhas e da cultura da soja. Ci. Rural, v. 34, p. 13-18, 2004

RIZZARDI, M. A. et al. Perdas de rendimento de grãos de soja causadas por interferência de picão-preto e guanxuma. Ci. Rural, v. 33, n. 4, p. 621-627, 2003.

SALTON, J. C.; MIELNICZUK, J. Relações entre sistemas de preparo, temperatura e umidade de um Podzólico Vermelho-Escuro de Eldorado do Sul (RS). R. Bras. Ci. Solo, v. 19, n. 2, p. 313-319, 1995.

SANTOS, J. B. et al. Atividade microbiana do solo após aplicação de herbicidas em sistemas de plantio direto e convencional. Planta Daninha, v. 23, n. 4, p. 683-691, 2005.

SILVA, A. A. et al. Aspectos fitossociológicos da comunidade de plantas daninhas na cultura do feijão sob diferentes sistemas de preparo do solo. Planta Daninha, v. 23, n. 1, p. $17-24,2005$

STENBERG, B. Monitoring soil quality of arable land: microbiological indicators. Soil Plant Sci., v. 49, n. 1, p. 124, 1999.

VANDEVENDER, K. W.; COSTELLO, T. A.; SMTTH JR., R. J. Model of rice (Oryza sativa) yield reduction as a function of weed interference. Weed Sci., v. 45, n. 2, p. 218224, 1997.

Planta Daninha, Viçosa-MG, v. 26, n. 1, p. 65-71, 2008 